\title{
Prevention of Diabetes Complications
}

\author{
Nepton Soltani \\ Molecular Medicine Research Center, Hormozgan University of Medical Science,
}

Iran

\section{Introduction}

The constellation of abnormalities caused by insulin deficiency is called diabetes mellitus. The cause of clinical diabetes is always a deficiency of the effect of insulin at the tissue level. Type I diabetes or insulin- dependent diabetes mellitus (IDDM), is due to insulin deficiency caused by autoimmune destruction of the B cell in the pancreatic islets, and it accounts for 3$5 \%$ of cases and usually presents in children. Type 2 diabetes, or non-insulin-dependent diabetes mellitus (NIDDM), is characterized by the dysregulation of insulin release from the $\mathrm{B}$ cells, along with insulin resistance in peripheral tissues such as skeletal muscle, brain, and liver. Type 2 diabetes usually presents in overweight or obese adults.

The incidence of diabetes in the human population has reached epidemic proportions worldwide and it is increasing at the rapid rate.150 million people in 2000, which is predicted to rise to 220 million in 2010.

In animals, it can be produced by pancreatectomy; by administration of alloxan, streptozocin, or other toxins that in appropriate doses cause selective destruction of the beta cells of the pancreatic islets; by administration of drugs that inhibit insulin secretion; and by administration of anti-insulin anti-bodies. Strains of mice, rats, hamsters, guinea pigs, miniature swine, and monkeys that have a high incidence of spontaneous diabetes mellitus have also been described.

Diabetes is characterized by polyuria, polydipisa, weight loss in spite of polyphagia, hyperglycemia, glycosuria, ketosis, acidosis, and coma. Widespread biochemical abnormalities are present, but the fundamental defects to which most of the abnormalities can be traced are 1) reduced entry of glucose into various peripheral tissues and 2) increased liberation of glucose into the circulation from the liver. Therefore there is an extracellular glucose excess and, in many cells, an intracellular glucose deficiency a situation that has been called starvation in the midst of plenty. Also, the entry of amino acids into muscle is decreased and lipolysis is increased.

\section{Diabetes complication}

Diabetic complications are divided to two parts: 1) metabolic complication and 2) vascular complication.

\subsection{Metabolic complication}

Obesity is increasing in incidence, and relates to the regulation of food intake and energy balance and overall nutrition. It is special relation to disordered carbohydrate metabolism 
and diabetes. As body weight increase, insulin resistance increase, that is, there is a decreased ability of insulin to move glucose into fat and muscle and shut off glucose release from liver. The liver takes up glucose from the bloodstream and stores it as glycogen, but because the liver contains glucose 6- phosphates it also discharges glucose into the bloodstream. Insulin facilitates glycogen synthesis and inhibits hepatic glucose output. When the plasma glucose is high, insulin secretion is normally increased and hepatic glucogenesis is decreased. This response dose not occurs in type I and II diabetes.

When plasma glucose is episodically elevated over time, small amounts of hemoglobin A are nonenzymatically glycated to from $\mathrm{HbA1c}$. Careful control of the quently $\mathrm{HbA1c}$ level is measured clinically as an integrated index of diabetic control for the 4 to 6 weeks period before the measurement. Many studies showed that the mean $\mathrm{HbA1c}$ value was a good predictor of ischemic heart disease. In particular, the multivariate analysis showed that per each $1 \%$ increment in $\mathrm{HbA} 1 \mathrm{c}$ there was a $10 \%$ increase in the risk of coronary heart disease. Some studies believed that $1 \%$ reduction in $\mathrm{HbA1c}$ level led to a $16 \%$ reduction in the occurrence of myocardial infarction.

Peripheral neuropathy, often expressed as hypersensitivity to painful stimuli, is among the most common complications of diabetes that develops in up to $60 \%$ of patients. It occurs in both type I and II diabetes and its incidence is linked to duration of disease. Neuropathic pain is a chronic or persistent pain characterized by alterations in pain perception, enhanced sensitivity to noxious stimuli (hyperalgesia) and abnormal pain sensitivity to previously non-painful stimuli (allodynia). Though the pathophysiology of neuropathy in diabetes has not been fully elucidated, hyperglycemia induced by diabetes is though to contribute to its development and maintaining good glycemic control could restrict the onset and progression of diabetic neuropathy.

\subsection{Vascular complication}

Hyperglycemia has a direct, harmful effect on the cardiovascular system requires, at the very least, a link between acute hyperglycemia and one or more risk factors for cardiovascular disease (CVD). Associated with obesity there is hyperinsulinemia, high circulating triglyceride and low HDL, and accelerated development of atherosclerosis. In diabetes, the plasma cholesterol level is usually elevated and this plays a role in the accelerated development of the atherosclerotic vascular disease that is a major long-term complication of diabetes in humans.

As usual diabetes is characterized by a high incidence of CVD, and poor control of hyperglycemia appears to play a significant role in the development of CVD in diabetes. Recently, there has been increasing evidence that the postprandial state is an important contributing factor to the development of atherosclerosis. In diabetes the postprandial phase is characterized by a rapid and large increase in blood glucose levels, and the possibility that these postprandial hyperglycemic spikes may be relevant to the pathophysiology of the late diabetes complications.

Insulin resistance (IR) has profound, negative effects on the function of arteries and arterioles throughout the body. In addition to the obvious link between IR and the development of type 2 diabetes, IR-associated dysfunction of resistance vessels is associated with arterial hypertension and vascular occlusive diseases. IR affects arteries and arterioles at both the endothelium and smooth muscle levels. For example, IR causes reduced responsiveness of vascular smooth muscle to dilator agents; predominantly due to impaired potassium channel function. 
Vascular disease is one of the complicating features of diabetes mellitus. Several prospective studies have indicated that hypertension in diabetic patient's takes place at a rate more than twice compared to the normal population. The hypertension is also considered an independent risk factor for cardiovascular mortality in patients with diabetes. It has been suggested that alterations in the reactivity of blood vessels to neurotransmitters and circulating hormones are responsible for the cardiovascular complications of diabetes. Some studies showed that $\mathrm{Ca} / \mathrm{Mg}$ ratio is a marker of vascular tone; its increase represents increased vascular reactivity and atherogenic risk. Atherogenic lesion is poorly correlated with serum cholesterol level and is highly dependent on plasma magnesium level and $\mathrm{Ca} / \mathrm{Mg}$ ratio. Pervious studies showed that $\mathrm{Ca} / \mathrm{Mg}$ ratio increase in diabetic case. Endothelial function is altered early in diabetes. It has been demonstrated that in diabetic subjects, the vasodilating response to stimuli is diminished and that this anomaly is related to glycemic control. In vivo studies have demonstrated that hyperglycemic spikes induce, in both diabetic and normal subjects, an endothelial dysfunction. This effect of hyperglycemia is probably linked with a reduced production/bioavailability of nitric oxide (NO), since hyperglycemia-induced endothelial dysfunction is counterbalanced by arginine. Furthermore, it is very interesting that a rapid decrease of flow-mediated vasodilation has been shown in the postprandial phase in type II diabetes patients and that the decrease correlated inversely with the magnitude of postprandial hyperglycemia.

\section{Prevention of diabetes complications}

Type I diabetes usually develops before the age 40 , patients with this disease are not obese and they have a high incidence of ketosis and acidosis. Various anti-B cell antibodies are present in plasma, but the current thinking is that type I diabetes is primarily a $\mathrm{T}$ lymphocyte-mediated disease. But type II diabetes is the most common type of diabetes and is usually associated with obesity. It usually develops after age 40 and is not associated with total loss of the ability to secrete insulin. It has an insidious onset, is rarely associated with ketosis, and is usually associated with normal beta-cells morphology and insulin content if the beta-cells have not become exhausted. So it seems we should look for different methods for prevention of type I and II diabetes.

\subsection{Diabetes diet}

Several lifestyle factors affect the incidence of type 2 diabetes. Obesity and weight gain dramatically increase the risk, and physical inactivity further elevates the risk, independently of obesity. Cigarette smoking is associated with a small increase and moderate alcohol consumption with a decrease in the risk of diabetes. In addition, a low-fiber diet with a high glycemic index has been associated with an increased risk of diabetes, and specific dietary fatty acids may differentially affect insulin resistance and the risk of diabetes.

Excess body fat is the single most important determinant of type II diabetes. Weight control would be the most effective way to reduce the risk of type II diabetes, but current strategies have not been very successful on a population basis, and the prevalence of obesity continues to increase. The public generally does not recognize the connection between overweight or obesity and diabetes. Thus, greater efforts at education are needed.

Low-fat vegetarian and vegan diets are associated with reduced body weight, increased insulin sensitivity, and reductions in cardiovascular risk factors. The potential cardiovascular benefits of vegetarian and vegan diets may be especially important for 
individuals with diabetes, for whom cardiovascular disease is a main cause of premature mortality; the effects of such diets on cardiovascular risk factors appear to be similar in individuals with and without diabetes.

Prior studies have shown that near-vegetarian diets reduce the need for insulin and oral medications in individuals with type 2 diabetes. We previously reported that in individuals with type 2 diabetes, a low-fat, vegan diet was associated with improved glycemic control, weight loss, and improved plasma lipid control during a 22-wk study period. What is particularly critical in diabetes management is long-term improvement in clinical measures, particularly glycemia and cardiovascular risk factors. Well-planned low-fat vegan diets are nutritionally adequate and, in research studies, have shown acceptability comparable with that of other therapeutic diets, suggesting they are suitable for long-term use.

\subsection{Immunosupression drug}

If type one diabetic patient give immunosupression drugs like cyclosporine ameliorate early in the disease, before all beta cells are lost can be useful for prevention of disease. But chose the low fat and low carbohydrate diets could be useful for prevention of type 2 diabetes.

\section{Magnesium}

Some studies indicated that magnesium is a novel factor implicated in the pathogenesis of the complication of diabetes. Magnesium plays a fundamental role as a cofactor in various enzymatic reactions of energy metabolism. Magnesium is a cofactor in cell membrane glucose-transporting mechanisms, as well as in various enzymes in carbohydrate oxidation. It is also involved, at multiple levels, in insulin secretion, binding and activity. Magnesium deficit has been described in patients with type I diabetes. Hypomagnesemia can also be the cause or a result of diabetes complications. If it is followed by diabetes, osmotic diuresis may play a role in the mechanisms responsible for magnesium deficiency. Magnesium loss may be linked to the development of diabetes complications via a reduction in the rate of inositol transport and its subsequent intracellular depletion that might enhance the development of complications. Studies showed that the administration of magnesium corrected hyperglycemia and has brought blood glucose back to normal levels within $24 \mathrm{~h}$ of its administration. Moreover, magnesium appears to have some reparative effect on the pancrease of diabetic case. Accordingly, during long-term treatment, pancreatic repair may have an effective role in the control of plasma glucose levels. Magnesium also is a necessary cofactor for many enzymes which is involved in lipid metabolism. Mg-deficiency enhances catecholamine secretion which result in an increase in lipolysis and blood plasma magnesium has been shown to decrease when lipolysis is increased. Enhancement in lipolysis and subsequent elevation of plasma free fatty acids levels may lead to an increase in hepatic VLDL and triglycerides synthesis and secretion and elevated plasma triglyceride concentration. The hepato-biliary pathway is the main rout for removal of cholesterol from the body. Bile flow is significantly lower in Mg-deficient subject than in controls and the cholesterol concentration in bile is decreased. Magnesium administration could decrease triglycerides, cholesterol and LDL cholesterol and also increased HDL cholesterol. The decrease in serum triglycerides was associated with the change in serum total $\mathrm{Mg}$ concentration. Other supporting evidence is accumulating for the role of magnesium in the modulation of serum lipids and lipids uptake in macrophages. Studies showed that increase 
in plasma endothelin I due to magnesium deficiency and a direct effect of magnesium deficiency on vascular smooth muscle are involved in the elevation of vascular tone in diabetic pateint. Elevated vascular tone can contribute to increased blood pressure. Some studies have observed that systolic and diastolic blood pressure and mean arterial blood pressure in Mg-treated chronic diabetic subject are lower than in chronic diabetic. The administration of magnesium can decrease vascular bed sensitivity to phenylephrine and decrease $\mathrm{Ca} / \mathrm{Mg}$ ratio. Studies also showed that magnesium decreases collagen thickness, intima/media thickness and the lumen/ media ratio in aorta. This suggests that the administration of magnesium can decrease blood pressure and prevent vascular morphological changes and decrease in vascular sensitivity to neurotransmitter. Hemoglobin deficiency is observed in diabetic subjects. This can probably be explained by the inhibition of $ð$-aminolevulinate dehydratase (ð-ALA-D) in diabetes. Studies have found that this enzyme is inhibited by glycation of the active site lysine residue involved in Schiff's base formation with the first $\partial$-ALA-D molecule. Magnesium administration reduces this glycation via blood glucose reduction and, thus, prevents hemoglobin deficiency. So it seems that magnesium administration may play in the management of diabetes and the prevention of its vascular complications in diabetic patients.

\section{Glucagone-like peptide-1 (GLP-1)}

Type I diabetes is a complex disease that results from an autoimmune T-lymphocytedependent islet infiltration and destruction of islet beta- cells, with consequent insulin deficiency and dependence on exogenous insulin treatment. A strikingly decreased functional beta- cell mass owing to apoptosis constitutes the histopathological hallmark of the disease at diagnosis. Recently, strategies employing beta-cell growth factors to enhance functional beta-cell mass and restore insulin secretion have been proposed for the treatment and prevention of diabetes. One such promising beta-cell growth factor identified is glucagone-like peptide-1 (GLP-1). GLP-1 is an insulinotropic hormone that is secreted from intestinal L-cell in response to nutrient ingestion and promotes nutrient absorption via regulation of islet hormone secretion. GLP-1 receptor is expressed mainly by pancreatic beta-cells, and to some extent in other tissues like lung, kidney and brain. GLP-1 enhances pancreatic islet beta-cell proliferation and inhibits beta-cell apoptosis in a glucose-dependent fashion. Other actions of GLP-1 are to decrease glucagons secretion and gastric emptying. Together, all these actions tend to lower the plasma glucose concentration and to limit plasma glucose rises with meals. GLP-1 is another gastrointestinal hormone that is also expressed in the hypothalamus and brainstem. Their CNS actions are to decrease food intake, decrease water intake, and increase diuresis. However, native GLP-1 has a short circulating half-life (less than $2 \mathrm{~min}$ ) that results mainly from rapid enzymatic inactivation by dipeptidyl-peptidase IV (DPP- IV), and/ or renal clearance. Therefore, continuous subcutaneous infusion by pump is necessary to maintain GLP-1 action. DPP- IV-resistant GLP-1 analogues and other formulations appear to be promising therapeutic drug candidates for the treatment and prevention of diabetes, but these peptides require once or twice-daily injections and/or combination therapies with oral diabetic medications. Scientifics recently developed a novel GLP-1 fusion peptide consisting of the active human GLP-1 molecule and the murine IgG1 constant heavy-chain (IgG-Fc). Plasmid-based, electroporation-enhanced intramuscular gene therapy with GLP-1/IgG-Fc improved insulin production and normalized glucose tolerance in type one or two diabetes. 


\section{Gama amino butyric acid (GABA)}

Gama amino butyric acid (GABA) is an important neurotransmitter which was initially identified in the central nervous system and is also found in islet beta-cells. GABA has an important role in pathogenesis of diabetes. Excessive secretion of glucagon is a major contributor to the development of diabetic hyperglycemia. Secretion of glucagon is regulated by various nutrients, with glucose being a primary determinant of the rate of alpha-cell glucagon secretion. The intra-islet action of insulin is essential to exert of insulin, glucose is not able to suppress glucagons release in vivo. However, the precise mechanism by which insulin suppresses glucagon secretion from alpha-cells is unknown. Studies showed that insulin induces activation of GABAA Akt kinase-dependent pathway. This leads to membrane hyperpolarization in the alpha-cells and, ultimately, suppression of glucagon secretion. Researchers propose that defects in this pathway contribute to diabetic hyperglycemia. It is well known that the secretion of glucagon is abnormal in human type I diabetes patients. The patients do not secrete glucagon in response to hypoglycemia and they have an exaggerated response of glucagon to stimuli such as arginine infusion and a protein meal. In studies of patients with type I diabetes there are indications of an increase in alpha cell numbers. GABA decreases in diabetic patients. Some studies indicated that a reduction in cellular GABA level is more sensitive than insulin as a marker for the presence of dead beta-cells in isolated preparations. Pancreatic GABA content also rapidly decreased after diabetes induction and remained unaffected by $12 \mathrm{~h}$ of hyperglycemia. It seems that GABA therapy can has some beneficial effect to prevention or treatment type I diabetes.

\section{Antioxidants}

Increasing evidence in both experimental and clinical studies suggests that oxidative stress play a major role in the pathogenesis of both types of diabetes mellitus. Diabetes is usually accompanied by increased production of free radicals or impaired antioxidant defenses. Mechanisms by which increased oxidative stress is involved in the diabetic complication are partly known, including activation of transcription factors, advanced glycated end products (AGEs), and protein kinase $\mathrm{C}$.

Excessively high levels of tree radicals cause damage to cellular proteins, membrane lipids and nucleic acids, and eventually cell death. Various mechanisms have been suggested to contribute to the formation of these reactive oxygen-free radicals. Glucose oxidation is believed to be the main source of free radicals. In its enediol form, glucose is oxidized in a transition-metal-dependent reaction to an enddiol radical anion that is converted into reactive ketoaldehydes and to superoxide anion radicals. The superoxide anion radicals undergo dismutation to hydrogen peroxide, which if not degraded by catalase or glutathione peroxidase, and in the presence of transition metals, can lead to production of extremely reactive hydroxyl radicals. Superoxide anion radicals can also react with nitric oxide to form reactive peroxynitrite radicals. Hyperglycemia is also found to promote lipid peroxidation of LDL by a superoxide- dependent pathway resulting in the generation of free radicals. Another important source of free radicals in diabetes is the interaction of glucose with proteins leading to the formation of Amadori product and then advanced glycation endproducts (AGEs). These AGEs, via their receptors (RAGEs), inactivate enzymes and alter their structures and functions, promote free radical formation, and quench and block 
antiproliferative effects of nitric oxide. By increasing intracellular oxidative stress, AGEs activate the transcription factor $\mathrm{NF}-\mathrm{kB}$, thus promoting up-regulation of various NF-kB controlled target genes. NF-kB enhances production of nitric oxide, which is believed to be a mediator of islet beta cell damage.

Considerable evidence also implicates activation of the sorbitol pathway by glucose as a component in the pathogenesis of diabetic complications, for example, in lens cataract formation or peripheral neuropathy. Efforts to understand cataract formation have provoked various hypotheses. In the aldose reductase osmotic hypothesis, accumulation of polyols initiates lenticular osmotic changes. In addition, oxidative stress is linked to decreased glutathione levels and depletion of NADPH levels. Alternatively, increased sorbitol dehydrogenase activity is associated with altered $\mathrm{NAD}^{+}$levels, which results in protein modification by nonenzymatic glycosylation of lens proteins.

Mechanisms linking the changes in diabetic neuropathy and induced sorbitol pathway are not well delineated. One possible mechanism, metabolic imbalances in the neural tissues, has been implicated in impaired neurotrophism, neurotrsnsmission changes, Schwann cell injury, and axonopathy.

While on the one hand hyperglycemia engenders free radicals, on the other hand it also impairs the endogenous antioxidant defense system in many ways during diabetes. Antioxidant defense mechanism involves both enzymatic and nonenzymatic strategies. Common antioxidants include the vitamins A, C and E, antioxidant minerals (copper, zinc, manganese, and selenium), and the cofactors (folic acid, vitamins B1, B2, B6, B12). They work in synergy with each other and against different types of free radicals. Vitamin $\mathrm{E}$ suppresses the propagation of lipid peroxidation; vitamin C with vitamin E inhibits hydroperoxide formation; metal complexing agents, such as penicillamine, bind transition metal involved in some reactions in lipid peroxidation and inhibit Fenton and Haber-weisstype reactions; vitamins $\mathrm{A}$ and $\mathrm{E}$ scavenge free radicals.

\section{Herbal medicine}

Recently, the search for appropriate hypoglycemic agents has been focused on plants. Many herbal medicines have been recommended for the treatment of diabetes. Plant drugs are frequently considered to be less toxic and free from side effect than synthetic ones. The leaf of Psidium guava, Teucrium polium, Cinnamon and Garlic are used traditionally in many countries to manage, control and treat of diabetes. Some recent studies have shown that administration of Psidium guava or Teucrium polium leaves decrease blood glucose via enhance insulin secretion.

Psidium guajva Linn., commonly known as guava, is a native plant in tropical American and has long been naturalized in south east Asia and in south of Iran. Different parts of the plant are used in traditional medicine for the treatment of various human aliments such as wound, ulcers, bronchitis, cyesores and diarrhea. In folklore guava has been used for a long time as a medicinal herb to cure diabetes mellitus. Many people in some countries including Japan, Taiwan and Iran boil guava leaves in water and drink the exact as a folk medicine for diabetes and hypertension. Psidium guajava leaves have a beneficial effects on diabetes metabolic syndrome and vascular complications.

Photochemical analysis of Psidium guajava leaves have revealed the presence of flavonoids, which include quercetin and its derivatives (guajaverin, isoquercitrin, hyperin, quercitrin, avicularin), morin and its derivatives (morin-3-O-a-L-lixopyranoside and morin-3-O-a-L- 
arabopyranoside), rutin, myricetin, luteolin and kaempferol. The leaves of the plant have also been shown to contain essential oil, fixed oil, volatile oil, saponin, resin, tannin, triterpenoids, asiatic acid and ellagic acid.

The relaxant effect of Psidium guajva Linn., on endothelium-intact aortic rings were only partially inhibited by N-nitro-L-arginine methyl ester (L-NAME), a nitric oxide synthase inhibitor, suggesting that the vasorelaxant effect of Psidium guajva Linn., on aortic rings is probably mediated via both endothelium-derived relaxing factor (EDRF)-dependent and EDRF-independent mechanisms but it seems this mechanism is not follow in diabetic rat vessel.

Teucrium polium L. is one of 300 species of the genus Teucrium and found mainly in the Mediterranean and Western Irano-Turanian sphere. It is widely distributed in Iran, Jordan and Palestine. The leaves 1-3 cm long, are sessile, oblong or linear, the stems are ending in a shortly paniculate or corymbose infoflorescences, corolla is white or pale cream colored. Several researchers have evaluated Teucrium polium grown in different geographic origin and it has flavonoids and iridoids. Hypoglycemic activity has been reported - in addition to the flavonoids- also for the volatile oils. Traditionally, especially in the Mediterranean countries and in Iran, Teucrium polium, is used for its antispasmodic and hypoglycemic activities by the native inhabitants and recommended by the herbalists. Anti-inflammatory, anti-hypertensive, antinociceptive, anti-ulcer and anorexic effects are other activities reported. Some investigators have reported reduction in blood glucose concentrations of animal diabetic model after treatment with a single i.v., i.p. and oral dose of Teucrium polium aqueous decoction. Some Iranian researchers have observed significant decrease in blood glucose in animal diabetic model after six weeks of consecutive oral treatment with ethanol/ water extract.

Spices such as Cinnamon display insulin-enhancing activity in vitro. Cinnamon can improve glucose metabolism and the overall condition of individuals with diabetes not only by hypoglycemic effects but also by improving lipid metabolism, antioxidant status, and capillary function. Aqueous extracts from Cinnamon have also been shown to increase in vitro glucose uptake and glycogen synthesis and to increase phosphorylation of the insulin receptor; in addition, these Cinnamon extracts are likely to aid in triggering the insulin cascade system. Because insulin also plays a key role in lipid metabolism, consumption of Cinnamon would lead to improved glucose and blood lipids in vitro. The mechanism of the effect of Cinnamon on glucose and blood lipids is not completely understood but the researchers believe that extracts of Cinnamon activated glycogen synthase, increased glucose uptake, and inhibited glycogen synthase kinase- $3 \beta$. Extracts of Cinnamon also activated insulin receptor kinse and inhibited dephosphorylation of the insulin receptor, leading to maximal phosphorylation of the insulin receptor. All of these effects would lead to increased insulin sensitivity. The extract of Cinnamon also has function as potent antioxidants, which would lead to additional health benefits of this substance.

Garlic was known to be effective in decreasing, cholesterol and can inhibit LDL-Oxidation. Many clinical trials have been conducted to determine the lipid-lowering effects of fresh garlic and garlic supplements. Garlic consumption also can decrease blood glucose in diabetic patients and has beneficial effect on diabetic vessel. It seems that daily Garlic consumption can be useful to prevent of diabetes. 


\section{References}

Abe A, Kawasoe C, Kondo Y, Sato K. 2003. Enhancement of norepinephrine-induced transient contraction in aortic smooth muscle of diabetic mice. Acta. Med. Okayama 57(1): 45-8

Adeghate E, Ponery AS. 2002. GABA in the endocrine pancreas: cellular localization and function in normal and diabetic rats. Tissue Cell. 34(1):1-6.

Afifi FU, Al-Khalidi B, Khalil E. 2005. Studies on the in vivo hypoglycemic activities of two medicinal plants used in the treatment of diabetes in Jordanian traditional medicine following intranasal administration. J. Ethnopharmacol. 100: 314-318

Ajay M, Achike FI, Mustafa AM, Mustafa MR. 2006. Effect of quercetin on altered vascular reactivity in aorta isolated from sterptozotocin-induced diabetic rats. Diabetes Res. Clin. Pract. 73: 1-7

Altura BM, Altura BT. 1995. Magnesium and cardiovascular biology an important link between cardiovascular risk factors and atherogenesis. Cellular and Molecular Bio. Research. 41(5): 245-271

Altura BM, Altura BT. 1991. Cardiovascular risk factors and magnesium: relationships to atherosclerosis, ischemic heart disease and hypertension. Magnes.Trace. Elem. 10: 182-192.

Anetor, JI, Senjobi A, Ajose OA, Agbedana, E.O. 2002. Decreased serum magnesium and zinc levels: atherogenic implications in type-2 diabetes mellitus in Nigerians. Nutr.Health 16: 291-300.

Anwar N, Mason DF. 1982. Two actions of gamma-aminobutyric acid on the responses of the isolated basilar artery from the rabbit. Br J Pharmacol. 75(1): 177-81.

Ashraf R, Aamir K, Shaikh AR, Ahmed T. 2005. Effect of Garlic on dyslipidemia in patients with type 2 diabetes mellitus. J Ayub Med Coll Abbottabad. 17(3): 1-5

Baluchnejadmojarad T, Roghani M, Homayounfar H, Hosseini M. 2003. Benefical effect of aqueous garlic extract on the vascular reactivity of streptozotocin-diabetic rats. J of Ethnopharmacol. 85: 139-144

Begum S, Hassan SI, Ali SN, Siddiqui BS. 2004. Chemical constituents from the leaves of psidium guajava. Nat Prod Res. 18: 135-140

Borboni P, Porzio O, Fusco A, Sesti G, Lauro R, Marlier LN. 1994. Molecular and cellular characterization of the GABAA receptor in the rat pancreas. Mol Cell Endocrinol. 103(1-2):157-63

Busija DW, Miller AW, Katakam P, Simandle S, Erdös B. 2004. Mechanisms of vascular dysfunctionin insulin resistance. Curr Opin Investig Drugs. 5(9): 929-35

Ceriello A. 2005. Postprandial hyperglycemia and diabetes complications. Is it time to treat? Diabetes. 54:1-7

Chiwororo DH, Ojewole J. 2008. Biphasic effect of psidium guajava Linn. (Myrtaceae) leaf aqueous extract on rat isolated vascular smooth muscle. Smooth Muscle Res. 44(6): 217-229

Corica F, Allegra A, Di BA, Giacobbe MS, Romano G, Cucinotta D, Buemi M, Ceruso D. 1994. Effects of oral magnesium supplementation on plasma lipid concentrations in patients with non-insulin-dependent diabetes mellitus. Magnes. Res. 7: 43-47 
de Valk HW, Verkaaik R, van Rijn HJ, Geerdink RA, Struyvenberg A. 1998. Oral magnesium supplementation in insulin-requiring Type 2 diabetic patients. Diabet.Med. 15: 503507

Diederich D, Skopec J, Diederich A, Dai FX. 1994. Endothelial dysfunction in mesenteric resistance arteries of diabetic rat: role of free radical. Am J. Physiol. 266: H1153H1161

Djurhuus MS, Henriksen JE, Klitgaard NA, Blaabjerg O, Thye-Ronn P, Altura BM, Altura BT, Beck-Nielsen H. 1999. Effect of moderate improvement in metabolic control on magnesium and lipid concentrations in patients with type 1 diabetes. Diabetes Care. 22: 546-554.

Djurhuus MS, Klitgaard NAH, Pedersen KK, Blaabjerg O, Altura BM, Altura BT, Henriksen JE. 2001. Magnesium reduces insulin-stimulated glucose uptake and serum lipid concentrations in type 1 diabetes. Met.Clin. Exp 50: 1409-1417.

Dong H, Kumar M, Zhang Y, Gyulkhandanyan A, Xiang YY, Ye B. 2006. Gammaaminobutyric acid up- and downregulates insulin secretion from beta cells in concert with changes in glucose concentration. Diabetologia. 49(4):697-705

Duarte J, Perez-Vizcaino F, Jimenez J, Tamargo J, Zarzuelo A. 1993. Vasodilatory effects of flavonoids in rat aortic smooth muscle. Structure-activity relationships. Gen. Pharmacol. 24: 857-862

Eidi A, Eidi M, Esmaeili E. 2006. Antidiabetic effect of garlic (Allium Sativum L.) in normal and sterptozotocin-induced diabetes rats. Phytomedicine. 13: 624-629

Ferriola PC, Cody V, Middleton EJR. 1989. Protein kinase C inhibition by flavonoids. Kinetic mechanism and structure-activity relationships. Biochem. Pharmacol. 38: 1617-1624

Franklin IK, Wollheim CB. 2004. GABA in the endocrine pancreas: its putative role as an islet cell paracrine-signalling molecule. J Gen Physiol. 123(3):185-90.

Giugliano D, Cericllo A, Paolisso G. 1996. Oxidative stress and diabetic vascular complication. Diabetes Care. 19: 257-267

Giugliano D, Marfella R, Coppola I, Verrazzo G, Acampora R, Giunta R, Nappo F, Lucarelli CD, Onofrio F. 1997. Vascular effects of acute hyperglycemia in humans are reversed by L-arginine evidence for reduced availability of nitric oxide during hyperglycemia. Circulation. 95:1783-1790

Gladkevich A, Korf J, Hakobyan Vp, Melkonyan KV. 2006. The peripheral GABAergic system as a target in endocrine disorders. Auton Neurosci. 124(1-2):1-8.

Gutierrez RMP, Mitchell S, Solie RV. 2008. Psidium guajava: a review of its traditional uses, phytochemistry and pharmacology. J. Ethnopharmacol. 117: 1-27

Hasanein P, Parviz M, Keshavarz M, Javanmardi K, Mansoori M, Soltani N. 2006. Oral magnesium administration prevents thermal hyperalgesia induced by diabetes in rats. Diabetes Res Clin Pract. 73(1): 17-22

Jarrett RJ. 1989. Cardiovascular disease and hypertension in diabetes mellitus. Diabetes/Metabolism Research and Reviews. 5: 547-558

Jenkins AJ, Klein RL, Chassereau CN, Hermayer KL, Lopes-Virella MF. 1996. LDL from patient with well-controlled IDDM is not more susceptible to in vitro oxidation. Diabetes. 45: 762-767 
Jenkins AJ, Lyons T, Zheng DY, Otvos JD, Lackland DT, Mcgee D, Garvey WT, Klein RL. 2003. Serum lipoproteins in the diabetes control and complications trial/epidemiology of diabetes intervention and complications cohort Associations with gender and glycemia. Diabetes Care 26: 810-818

Jensen KD, Jensen B, Lervang HH, Hejlesen OK. 2002. Diabetes patients' ability to estimate dietary carbohydrate content for use in a decision support system. Stud.Health Technol. Inform. 90: 649-654

Jorgensen RG, Russo I, Marttioli I, Moore WV. 1988. Early detection of vascular dysfunction in type I diabetes. Diabetes. 37:292-296

Kaneto H, Kajimoto Y, Miyagawa JI, Matsuoka TA, Fujitani Y, Umayahara Y, Hanafusa T, Matsuzawa Y, Yamasaki Y, Hori M. 1999. Beneficial effects of antioxidants in diabetes possible protection of pancreatic $\beta$-cells against glucose toxicity. Diabetes. 48: 2398-2406

Khan A, Khattak KN, Safdar M, Anderson R, Au Khan M. 2003. Cinnamon improves glucose and lipids of people with type 2 diabetes. Diabetes Care. 26(12): 32153218

Laight DW, Carrier MJ, Anggard EE. 2000. Antioxidant, diabetes and endothelial dysfunction. Cardiovasc. Res. 47: 457-464

Laires MJ, Moreira H, Monteiro CP, Sardinha L, Limao F, Veiga L, Goncalves A, Ferreira A, Bicho M. 2004. Magnesium, insulin resistance and body composition in healthy postmenopausal women. J. Am. College of Nutri 23: 510S-513S

Lal J, Vasudev K, Kela AK, Jain SK. 2003. Effect of oral magnesium supplementation on the lipid profile and blood glucose of patients with type 2 diabetes mellitus. J. Assoc. Physic. India. 51: 37-42

Laurant P, Touyz RM. 2000. Physiological and pathophysiological role of magnesium in the cardiovascular system: implications in hypertension. J. Hypertens. 18(9): 1177-91

Ligon B, Yang J, Morin SB, Ruberti MF, Steer ML. 2007. Regulation of pancreatic islet cell survival and replication by gamma-aminobutyric acid. Diabetologia. 50(4):764-73

Liu KH, Chan YL, Chan JC, Chan WB. 2005. Association of carotid intima-media thickness with mesenteric, preperitoneal and subcutaneous fat thickness. Atherosclerosis.179(2): 299-304

Liu KH, Chan Y.L, Chan WB, Chan JC, Chu CW. 2006. Mesenteric fat thickness is an independent dererminant of metabolic syndrome and identifies subjects with increased carotid intima-media thickness. Diabetes Care. 29(2): 379-84

Liu KH, Chan YL, Chan WB, Kong WL, Kong, MO, Chan JC. 2003. Sonographic measurement of mesenteric fat thickness is a good correlate with cardiovascular risk factors: comparison with subcutaneous and preperitoneal fat thickness, magnetic resonance imaging and anthropometric indexes. Int.J. Obes. Relat. Metab. Disord. 27: 1267-1273.

Maritim AC, Sanders RA, Watkins JB. 2003. Diabetes, oxidative stress and antioxidants: A review. J Biochem Molecular Toxicology. 17(1):24-38 
Mirghazanfari SM, Keshavarz M, Nabavizadeh F, Soltani N, Kamalinejad M. 2010. The effect of Teucrium polium L. Extracts on insulin release from in situ isolated perfused rat pancrease in newly modified isolation method: the role of $\mathrm{Ca}$ and $\mathrm{K}$ channels. Iranian Biomedical Journal. 14(4):178-185

Narendhirakannan RT, Subtanman S, Kandaswamy M. 2006. Some commonly used Indian plants on sterptozotocine induced diabetes in experimental rats. Clin Exp Pharmacol Physol. 33: 1150-1157

Obatomi DK, Bikomo EO, Temple VJ. 1994. Anti- diabetic properties of African mistletoe in sterptozotocin-induced diabetic rats. J Ethnopharmacol. 43(1): 13-70

Ojewole JA. 2005. Hypoglycemic and hypotensive effects of Psidium guajava Linn. (myrtaceae) leaf aqueous extract. Methods Find Exp clin pharmacol. 27(10): 689950

Okada Y, Taniguchi H, Schimada C. 1976. High concentration of GABA and high glutamate decarboxylase activity in rat pancreatic islets and human insulinoma. Science. 194(4265):620-2

Olatunji-Bello I, Odusanya AJ, Raji I, Ladipo CO. 2007. Contractile effect of aqueous extract of Psidium guajava leaves on aortic rings in rat. Fitoterapia 78: 241-243

Ozcelikay AT, Tay A, Guner S, Tasyaran V, Yildizoglu-Ar, N, Dincer UD, Altan VM. 2000. Reversal effects of L-arginine treatment on blood pressure and vascular responsiveness of streptozotocin-diabetic rats. Pharmacol. Res. 41(2): 201-9

Ozdem SS, Sadan G. 1999. Impairment of GABA-mediated contractions of rat isolated ileum by experimental diabetes. Pharmacology. 59: 165-170

Pari L, Umamaheswari J. 2000. Antihyperglycaemic activity of Musa Sapientum flowers: effect on lipid peroxidation in alloxan diabetic rats. Phytother. Res. 14: 1-3

Prudhomme GJ, Chang Y. 1999. Prevention of autoimmune diabetes by intramuscular gene therapy with a nonviral vector encoding an interferon-gamma receptor/ IgG1 fusion protein. Gene Therapy. 6: 771-777

Rasmussen H, Takuwa Y, Park S. 1987. Protein kinase C in the regulation of smooth muscle contraction. FSSEB J. 1: 177-185

Rayssiguier, Y, Gueux E, Durlach V, Durlach J, Nassir F, Mazur A. 1992. Magnesium and the cardiovascular system: I. New experimental data on magnesium and lipoproteins. In: Halpern,M.j. (Ed.), Molecular biology of atherosclerosis, Proceedings of the 57th European Atherosclerosis Society Meeting. John Libbey \& Company Ltd, Eastleigh, pp. 507-512

Reetz A, Solimena M, Matteoli M, Folli F, Takei K, De Camilli P. 1991. GABA and pancreatic beta-cells: colocalization of glutamic acid decarboxylase (GAD) and GABA with synaptic-like microvesicles suggests their role in GABA storage and secretion. EMBO J. 10(5):1275-84.

Saad MF, Greco S, Osei K, Lewin AJ, Edwards C, Nunez M, Reinhardt RR. 2004. Ragaglitazar improves glycemic control and lipid profile in type 2 diabetic subjects: a 12-week, double-blind, placebo-controlled dose-ranging study with an open pioglitazone arm. Diabetes Care. 27(6): 1324-9 
Shen SC, Cheng FC, Wu NJ. 2008. Effect of Guava (Psidium guajava Linn.) leaf soluble solids on glucose metabolism in type 2 diabetic rats. Phytother. Res. 22: 1458-1464

Shi Y, Kanaani J, Menard-Rose V, Ma YH, Chang PY, Hanahan D, et al. 2000. Increased expression of GAD65 and GABA in pancreatic beta-cells impairs first-phase insulin secretion. Am J Physiol Endocrinol Metab. 279 (3): E684-94

Singh RB, Rastogi SS, Mani UV, Seth J, Devi L. 1991. Does dietary magnesium modulate blood lipids? Biol. Trace. Elem. Res 30: 59-64.

Singh RB, Rastogi SS, Sharma VK, Saharia RB, Kulshretha SK. 1990. Can dietary magnesium modulate lipoprotein metabolism? Magnes.Trace. Elem. 9: 255-264

Soltani N, Keshavarz M, Dehpour AR. 2007. Effect of oral magnesium sulfate administration on blood pressure and lipid profile in streptozocin diabetic rat. Eur J Pharmacol. 560(2-3):201-5

Soltani N, Keshavarz M, Sohanaki H, Dehpour AR, Asl SZ. 2005. Oral magnesium administration prevents vascular complications in STZ-diabetic rats. Life Sci. 11 76(13): 1455-64

Soltani N, Kumar M, Glinka Y, Prud'homme GJ, Wang Q. 2007. Gene therapy of diabetes using a novel GLP-1/IgG1-Fc fusion construct normalizes glucose levels in $\mathrm{db} / \mathrm{db}$ mice. Gene Ther. 14(2):162-72

Soltani N, Keshavarz M, Minaii B, Mirershadi F, Zahed Asl S, Dehpour AR. 2005. Effect of administration of oral magnesium on plasma glucose and pathological changes in the aorta and pancrease of diabetic rats. Clin Exp Pharmacol Physiol. 32(8): 60410

Soltani N, Keshavarz M, Sohanaki H, Zahed Asl S, Dehpour AR. 2005. Relaxatory effect of magnesium on mesenteric vascular beds differs from normal and streptozotocin induced diabetic rats. Eur. J. Pharmacol 31 508(1-3): 177-81

Stamler J, Vaccaro O, Neaton JD, Wentworth D. 1993. The multiple risk factor intervention trial research group, diabetes, other risk factors and 12-yr cardiovascular mortality for men screened in the multiple risk factor intervention trial. Diabetes Care. 16:434-444

Sunagawa M, Shimada S, Zhang Z, Oonishi A, Nakamura M, Kosugi T. 2004. Plasma insulin concentration was increased by long-term ingestion of guava juice in spontaneous non-insulin-dependent diabetes mellitus (NIDDM) rats. Journal of health Sci. 50(6): 674-678

Suraez A. 1993. Decreased insulin sensitivity in skeletal muscle of hypomagnesium rats. Diabetologia. 36 (1): A82

Taniguchi H, Okada Y, Seguchi H, Shimada C, Seki M, Tsutou A. 1979. High concentration of gamma-aminobutyric acid in pancreatic beta cells. Diabetes. 28(7): 629-33

Tsai EC, Hirsch IB, Brunzell JD, Chait A. 1994. Reduced plasma peroxyl radical trapping capacity and increased susceptibility of LDL to oxidation in poorly controlled IDDM. Diabetes. 43: 1010-1014

Xu E, Kumar M, Zhang Y, Ju W, Obata T, Zhang N. 2006. Intra-islet insulin suppresses glucagon release via GABA-GABAA receptor system. Cell Metab. 3(1):47-58 
Yajnik CS. 2001. The insulin resistance epidemic in India: fetal origins, later lifestyle, or both? Nutr. Rev. 59: 1-9

Zizzo MG, Mulè F, Serio R. 2007. Functional evidence for GABA as modulator of the contractility of the longitudinal muscle in mouse duodenum: role of GABA(A) and GABA(C) receptors. Neuropharmacology. 52(8):1685-90. 


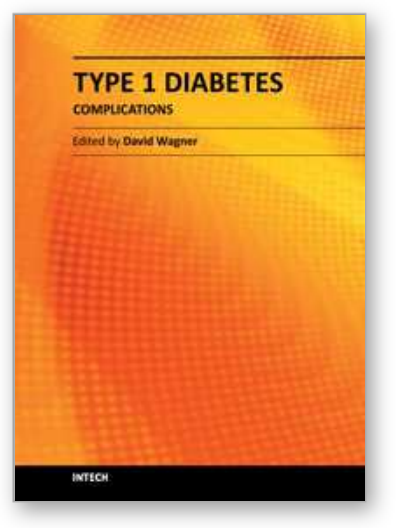

\section{Type 1 Diabetes Complications}

Edited by Prof. David Wagner

ISBN 978-953-307-788-8

Hard cover, 482 pages

Publisher InTech

Published online 25, November, 2011

Published in print edition November, 2011

This book is a compilation of reviews about the complication of Type 1 Diabetes. T1D is a classic autoimmune disease. Genetic factors are clearly determinant but cannot explain the rapid, even overwhelming expanse of this disease. Understanding etiology and pathogenesis of this disease is essential. The complications associated with T1D cover a range of clinical obstacles. A number of experts in the field have covered a range of topics for consideration that are applicable to researcher and clinician alike. This book provides apt descriptions of cutting edge technologies and applications in the ever going search for treatments and cure for diabetes.

\section{How to reference}

In order to correctly reference this scholarly work, feel free to copy and paste the following:

Nepton Soltani (2011). Prevention of Diabetes Complications, Type 1 Diabetes Complications, Prof. David Wagner (Ed.), ISBN: 978-953-307-788-8, InTech, Available from: http://www.intechopen.com/books/type-1diabetes-complications/prevention-of-diabetes-complications

\section{INTECH}

open science | open minds

\section{InTech Europe}

University Campus STeP Ri

Slavka Krautzeka 83/A

51000 Rijeka, Croatia

Phone: +385 (51) 770447

Fax: +385 (51) 686166

www.intechopen.com

\section{InTech China}

Unit 405, Office Block, Hotel Equatorial Shanghai

No.65, Yan An Road (West), Shanghai, 200040, China

中国上海市延安西路65号上海国际贵都大饭店办公楼405单元

Phone: +86-21-62489820

Fax: $+86-21-62489821$ 
(C) 2011 The Author(s). Licensee IntechOpen. This is an open access article distributed under the terms of the Creative Commons Attribution 3.0 License, which permits unrestricted use, distribution, and reproduction in any medium, provided the original work is properly cited. 